\title{
Prevention of anaemia in inner city toddlers by an iron supplemented cows' milk formula
}

\author{
A Daly, A MacDonald, A Aukett, J Williams, A Wolf, J Davidson, IW Booth
}

\begin{abstract}
There are few data to support the use of follow-on formulas in infants from the age of 6 months. In a prospective trial in a deprived inner city area of Birmingham 100 infants who were already receiving pasteurised cows' milk by 6 months of age were enrolled and randomised either to receive a follow-on formula or to continue on cows' milk from 6 months until 18 months. At 18 months of age the follow-on formula group returned to cows' milk and both groups were followed up until 24 months. Iron status, growth, and nutritional status were analysed at intervals of six months. At enrolment, no differences in haematological status were evident. However, by 12 months of age, $31 \%$ of the cows' milk group were anaemic (haemoglobin concentration < 110 g/1) compared with only $3 \%$ of those receiving follow-on formulas. At 18 months, 33\% of the cows' milk group were anaemic compared with only $2 \%$ of the follow-on formula group and by 24 months of age none of the follow-on formula group was anaemic, whereas $26 \%$ in the cows' milk group still had a haemoglobin of $<110 \mathrm{~g} / \mathrm{l}$. Mean corpuscular volume was significantly smaller and ferritin significantly lower in the cows' milk group at 12, 18, and 24 months. Dietary iron intake was higher in the follow-on formula group at 12 and 18 months but not at 24 months, when both groups were back on cows' milk. Infants and toddlers at high risk of iron deficiency are therefore unlikely to become anaemic if receiving a follow-on formula, although the relative merits of follow-on formula compared with an ordinary infant formula remain uncertain. (Arch Dis Child 1996;75:9-16)
\end{abstract}

Keywords: iron deficiency anaemia, reference nutrient intake, follow-on formula, pasteurised cows' milk.

Birmingham, Institute of Child Health IW Booth

Correspondence to: Anne Daly, Department of Dietetics, The Children's Hospital NHS Trust, Ladywood Middleway, Birmingham B16 8ET.

Accepted 8 April 1996

Iron deficiency anaemia is common in toddlers living in deprived conditions in inner cities in the developed world. Children from ethnic minorities are at particular risk. Twenty eight per cent of young children in Bradford whose families originally came from the Indian subcontinent, and $12 \%$ of corresponding white children, were found to be anaemic (haemoglobin concentration $<110 \mathrm{~g} / \mathrm{l}) .{ }^{1}$ These findings have been replicated in similar studies in the $\mathrm{UK}^{2-4}$ and in the United States. ${ }^{56} \mathrm{~A}$ number of dietary factors are probably important in promoting this high incidence: infrequent breast feeding, the use of weaning solids low in iron, and the frequent substitution of unmodified pasteurised milk for an iron supplemented formula from around 6 months of age. ${ }^{78}$ Not only is pasteurised cows' milk a poor source of iron, its use may also be associated with occult bleeding from the gut..$^{10}$

Iron deficiency in this high risk group of children in inner cities is therefore common, but the means of prevention remain uncertain. Health promotion exercises to educate caregivers in the use of iron sufficient weaning diets have been unsuccessful. Moreover, many caregivers prefer to give bottled pasteurised milk after the first few months because it is easy to use, even though iron supplemented normal infant formula is available free of charge to UK families receiving income support.

Follow-on formulas represent an alternative way of enhancing the iron intake of infants after 6 months of age. They contain more protein, iron, and vitamin $C$ than ordinary infant formulas, and were designed to complement a weaning diet from 6 months. Their composition and use have been approved by the European Society for Paediatric Gastroenterology and Nutrition, ${ }^{11}$ and although heavily marketed, we were not aware of any data to support their use in the prevention of iron deficiency anaemia in high risk toddlers. We therefore performed a longitudinal randomised study, comparing the haematological and dietary effects of a follow-on formula with pasteurised cows' milk, in a group of inner city toddlers whose mothers had already switched to pasteurised cows' milk by 6 months of age.

\section{Subjects and methods} SUBJECTS

the study was ethically acceptable, infants whose mothers had already switched their infants to cows' milk were recruited from a single health centre in inner Birmingham. All carers enrolled onto the study were given a verbal and written explanation of 
Table 1 Table showing nutrient composition of a standard infant formula, follow-on formula, and pasteurised cows' milk compared with the DHSS guidelines for infant formula composition

\begin{tabular}{|c|c|c|c|c|}
\hline $\begin{array}{l}\text { Nutrient/100 ml reconstituted } \\
\text { feed }\end{array}$ & $\begin{array}{l}\text { DHSS } \\
\text { guidelines } 28\end{array}$ & $\begin{array}{l}\text { Pasteurised } \\
\text { cows' milk }^{14}\end{array}$ & $\begin{array}{l}\text { Follow-on } \\
\text { formula }\end{array}$ & $\begin{array}{l}\text { Standard infant } \\
\text { formula }\end{array}$ \\
\hline Energy $(\mathrm{kcal})^{\star}$ & $65-75$ & 67 & 67 & 68 \\
\hline Protein $(\mathrm{g})$ & $1.2-2$ & 3.2 & 2 & 1.45 \\
\hline Fat $(\mathrm{g})$ & $2.3-5$ & 3.9 & 3 & 3.8 \\
\hline Carbohydrate (g) & 4.8-10 & 4.8 & 8 & 7 \\
\hline Sodium (mg) & $15-35$ & 55 & 30 & 17 \\
\hline Potassium (mg) & $50-100$ & 140 & 100 & 57 \\
\hline Calcium (mg) & $40-80$ & 115 & 72 & 39 \\
\hline Magnesium (mg) & $2.8-12$ & 11 & 7.1 & 5.2 \\
\hline Phosphorus (mg) & $15-60$ & 92 & 59 & 27 \\
\hline Iron (mg) & $0.07-0.7$ & 0.05 & 1.2 & 0.65 \\
\hline Copper $(\mu \mathrm{g})$ & $10-60$ & 0 & 41 & 42 \\
\hline Zinc (mg) & $0.2-0.6$ & 0.4 & 0.4 & 0.34 \\
\hline Chloride (mg) & $40-80$ & 100 & 65 & 45 \\
\hline Vitamin $\mathrm{A}(\mu \mathrm{g}) \dagger$ & $40-50$ & 52 & 80 & 100 \\
\hline Carotene $(\mu \mathrm{g})$ & 0 & 21 & 0 & 0 \\
\hline Vitamin D $(\mu \mathrm{g})$ & $0.7-1.3$ & 0.03 & 1.1 & 1 \\
\hline Thiamin B1 (mg) & 0.013 (NS) & 0.04 & 0.04 & 0.04 \\
\hline Riboflavin B2 (mg) & 0.03 (NS) & 0.17 & 0.15 & 0.06 \\
\hline Nicotinamide (mg) & 0.23 (NS) & 0.1 & 0.65 & 1.2 \\
\hline Tryptophan (mg) & 0 & 0.7 & 0 & 0 \\
\hline Vitamin C (mg) & 3 (NS) & 1 & 10 & 6.9 \\
\hline Vitamin E (mg) $\ddagger$ & 0.3 (NS) & 0 & 0.48 & 0.48 \\
\hline Vitamin B6 (mg) & 0.005 (NS) & 0.06 & 0.04 & 0.04 \\
\hline Vitamin B12 $(\mu \mathrm{g})$ & 0.01 (NS) & 0.4 & 0.2 & 0.14 \\
\hline Free folic acid $(\mu \mathrm{g})$ & NS & 0.06 & 7 & NS \\
\hline Folic acid $(\mu \mathrm{g})$ & 3 (NS) & 6.0 & 0 & 3 \\
\hline Pantothenic acid (mg) & 0.2 (NS) & 0.35 & 0.36 & 0.2 \\
\hline Biotin $(\mu \mathrm{g})$ & 0.5 (NS) & 1.9 & 3 & 1 \\
\hline
\end{tabular}

NS $=$ not specified

$\star 1 \mathrm{kcal}=4.18 \mathrm{~kJ}$

$\dagger=$ Retinol equivalent.

$\ddagger=$ Tocopherol. anthropometric assessments were made at enrolment, and at 12, 18, and 24 months of age. No significant differences were present between the two groups with respect to race, number of single parents, smokers and nonsmokers, those receiving income support, car or telephone ownership, maternal age, family size, accommodation, and maternal education.

The follow-on formula milk was supplied free of charge, while those remaining on cows' milk received an equivalent monthly payment.

The nutrient content of cows' milk, the follow-on formula used, and the standard infant formula made by the same manufacturer as the follow-on formula, are shown in table 1 .

\section{HAEMATOLOGICAL ASSESSMENTS}

Capillary blood was collected into lithiumheparin Sarstedt tubes. Ferritin assays were performed in the department of clinical chemistry at the Children's Hospital using a radioimmune assay (Becton Dickinson, radioimmunometric assay). A minimum volume of $25 \mu \mathrm{l}$ plasma was required. Haemoglobin and mean corpuscular volume (MCV) were measured in the department of haematology of the Children's Hospital, on a Coulter Max M, or if the samples were small on a Coulter MD18. A minimum volume of $200 \mu \mathrm{l}$ was needed to perform the analysis.

Subjects whose haemoglobin fell below 90 $\mathrm{g} / \mathrm{l}$ were removed from the study and referred to their general practitioner. deficiency with potential developmental delay. A power calculation showed that enrolling 47 subjects into each dietary group would provide a study power of $95 \%$ at a significance level of $5 \%$, with respect to determining a difference in haemoglobin concentration of $7.5 \mathrm{~g} / 1$ between groups.

The mean age at recruitment was 7.8 months ( range 5.7-8.6 months). There were 47 boys and 53 girls, and the population studied was $74 \%$ white, $24 \%$ Afro-Caribbean, and $2 \%$ Asian. Preterm infants were excluded.

The subjects lived in a socially deprived area with poor housing, high unemployment, and poor public amenities. There was only one bank and no large supermarkets within easy reach. The small local shops were expensive and carried limited stocks of food, particularly fresh fruit and vegetables. Seventy nine per cent of the subjects' mothers had left school at 16 years of age, and only $7 \%$ were educated beyond 18 years. Only $2 \%$ of the families in the study owned their own homes, and the rest of the families either rented from the local authority or were in a housing association scheme. The local authority homes were predominantly high rise tower blocks or maisonettes. Nineteen per cent of the families had a car, and $43 \%$ had telephones.

\section{STUDY DESIGN}

After recruitment, the infants were randomised either to receive follow-on formula or to continue on cows' milk until they were 18 months of age. At 18 months, those infants on follow-on formula were transferred back to cows' milk. Serial haematological, dietary, and

\section{DIETARY ASSESSMENTS}

Mothers were asked to weigh and record food intake over three days at enrolment, and at 12, 18 , and 24 months of age. Each of the mothers enrolled into the study was provided with a dietary diary and was shown how to weigh and record food and drink consumed. They were provided with Salter diet 32 electronic balance scales and the weighing accuracy of each of the mothers was checked at least once by one of us (AD) during the study period. Mothers who were unsure of the technique were visited every day at a meal time over the three day period. Subsequent analysis of the dietary records was performed using the 'Micro Diet' computer programme (Micro Diet 8.3, University of Salford), based on McCance and Widdowson's The Composition of Foods ${ }^{12}$ with supplementary data supplied by the Royal Society of Chemistry and food manufacturers.

\section{ANTHROPOMETRY}

Weight and length were measured at enrolment, and at 12,18, and 24 months. All measurements were obtained by the same person (AD). Nude weight was measured using portable electronic scales (Seca Model) to the nearest $0.01 \mathrm{~kg}$. Length was measured to the nearest $0.1 \mathrm{~cm}$ using a Harpenden stadiometer and Seca measuring stick. SD scores for weight for age, length for age, and weight for length were determined using the National Center for Health Statistics reference standards. ${ }^{13}$ 
Table 2 Haematological indices and plasma ferritin in the pasteurised cows' milk and follow-on formula groups

\begin{tabular}{|c|c|c|c|c|c|c|}
\hline & \multicolumn{2}{|c|}{ Mean (SD) haemoglobin $(g / l)$} & \multicolumn{2}{|c|}{ Mean (SD) MCV $(f)$} & \multicolumn{2}{|c|}{ Mean $(S D)$ ferritin $(\mu g / l)$} \\
\hline & Cows' milk & Follow-on formula & Cows' milk & Follow-on formula & Cows' milk & Follow-on formula \\
\hline $\begin{array}{l}\text { Enrolment } \\
12 \text { Months } \\
18 \text { Months } \\
24 \text { Months }\end{array}$ & $\begin{array}{l}120(11) \\
116(13)^{\star} \\
115(13) \dagger \\
118(10) \ddagger\end{array}$ & $\begin{array}{l}119(9) \\
124(9)^{\star} \\
123(7) \dagger \\
124(8) \ddagger\end{array}$ & $\begin{array}{l}75.0(4.5) \\
72.0(6.9) \oint \\
72.6(6.1) \rrbracket \\
74.1(5.7) \dagger\end{array}$ & $\begin{array}{l}75.9(4.3) \\
75.7(4.4) \oint \\
77.1(4.2) ף \\
78.0(3.4) \dagger\end{array}$ & $\begin{array}{l}34.6(22.2) \\
22.5(17.5) \\
15.9(12.2)^{\star \star} \\
14.9(11.3) \dagger \dagger\end{array}$ & $\begin{array}{l}33.2(22.9) \\
30.9(18.2) \\
30.5(17.0)^{\star \star} \\
32.4(24.8) \dagger\end{array}$ \\
\hline
\end{tabular}

p Values : ${ }^{\star}=0.0069 ; \dagger<0.0001 ; \ddagger=0.0017 ; \S=0.014 ; \uparrow=0.004 ;=0.04 ;{ }^{\star \star}=0.001 ; \dagger=0.016$.

STATISTICAL ANALYSES

Statistical analyses were performed using the Student's $t$ test, $\chi^{2}$ tests, and the Pearson correlation coefficient.

ETHICAL APPROVAL

Ethical approval was obtained from the South Birmingham Health Authority ethical committee. Informed written consent was obtained from caregivers.

\section{Results}

DROP OUTS

Sixteen infants failed to complete the study, nine on follow-on formula and seven on cows' milk: five because the family moved out of the area (two on follow-on formulas; three on cows' milk) and six because the mothers were unable to complete the dietary diaries to a satisfactory standard (four on follow-on formula; two on cows' milk). Two of the follow-on formula group were excluded because they failed to comply with the protocol: one child started cows' milk before 18 months and one child disliked the milk; one child in the follow-on formula group had thalassaemia trait and two in the cows' milk group were anaemic (haemoglobin $<90 \mathrm{~g} / \mathrm{l}$ ) and given oral iron by their general practitioner.

Eighty four children remained in the study. Infrequently, haematological data were missing due to insufficient blood sample volumes for all assays.

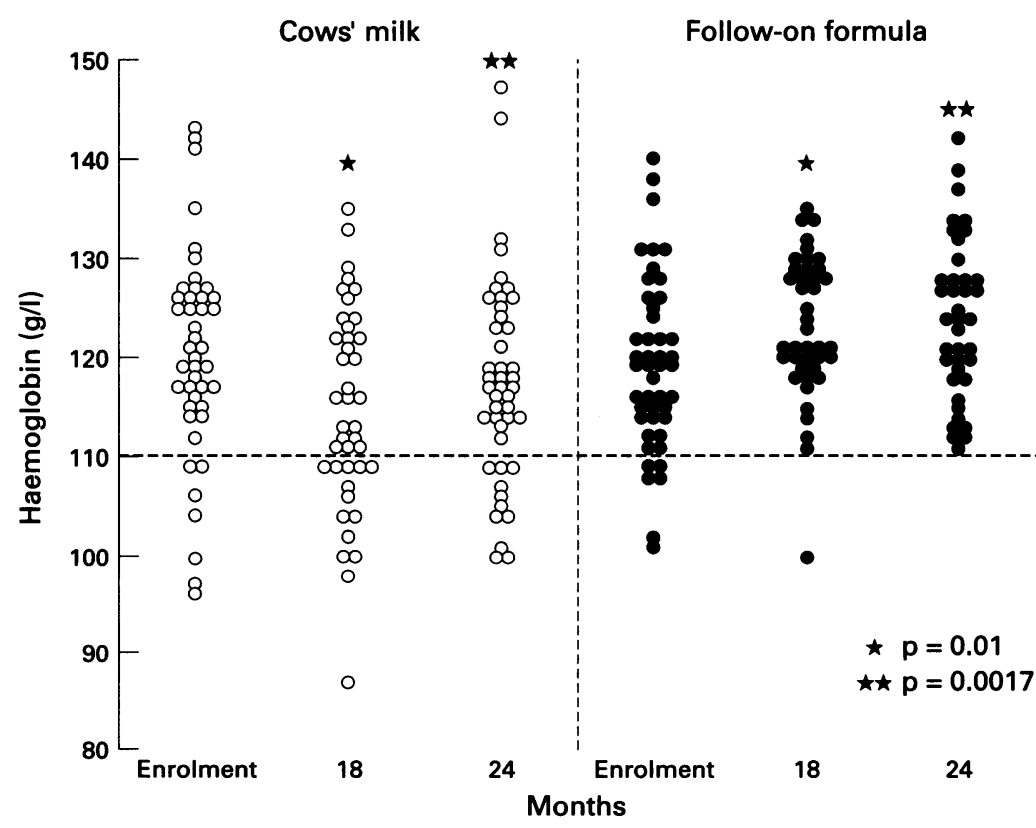

Figure 1 Change in haemoglobin concentration in the cows' milk and follow-on formula groups at enrolment and at 18 and 24 months.
HAEMATOLOGICAL INDICES

Haemoglobin (table 2; fig 1)

Although there was no difference in mean (SD) haemoglobin concentration between the two groups at enrolment, $16 \%$ of the cows' milk and $13 \%$ of the follow-on formula group were already anaemic (haemoglobin $<110 \mathrm{~g} / \mathrm{l}$ ) as defined by the World Health Organisation (WHO Geneva, 1975). By 12 months of age, major differences in mean haemoglobin concentration and in the frequency of anaemia had emerged between the two groups. Whereas only $3 \%$ of the group receiving follow-on formula were anaemic, $31 \%$ of the cows' milk group had a haemoglobin of $<110 \mathrm{~g} / 1$ $(p<0.0069)$. These differences were maintained at 18 months, when $2 \%$ of the follow-on formula group and $33 \%$ in the cows' milk group were anaemic $(\mathrm{p}<0.0001)$. At 24 months, when the follow-on formula group had been back on cows' milk for six months, $26 \%$ of the cows' milk group, but none of those originally on follow-on formula were anaemic $(p=0.0017)$.

\section{MCV (table 2; fig 2)}

At enrolment there was no difference in $\mathrm{MCV}$ between the two groups, but by $12(p=0.014)$ and 18 months $(p=0.004), M C V$ was significantly higher in the follow-on formula group. At 18 months, $29 \%$ of the cows' milk group had an MCV less than $70 \mathrm{fl}$ compared with only $2 \%$ in the follow-on formula group $(p=0.0004)$. By 24 months, when both groups were on cows' milk, MCV remained significantly lower in the cows' milk group $(p=0.0001)$. Twenty eight per cent in the cows' milk group had an MCV of less than $70 \mathrm{fl}$, compared with only $2 \%$ in the follow-on formula group.

In the cows' milk group a positive correlation was found between haemoglobin and MCV at enrolment $(r=0.66), 12$ months $(r=0.54)$, and 18 months $(r=0.76)$, but not at 24 months.

\section{Ferritin (table 2; fig 3)}

At enrolment there was no significant difference in plasma ferritin concentration between the two groups. However, at 12 months $(p=0.04)$ and at 18 months $(p=0.0001)$, ferritin was significantly higher in the follow-on formula group. Our hospital laboratory uses $8 \mu \mathrm{g} / 1$ as the lower limit of the reference range for ferritin (unpublished data). At 24 months, when both groups were on cows' milk, ferritin concentrations in the follow-on formula group remained significantly higher than in the cows' milk group $(p=0.0016)$. 
Table 3 Total combined nutrient intake from milk and solids for the pasturised cows' milk and follow-on formula groups expressed as mean (SD) intake per day

\begin{tabular}{|c|c|c|c|c|c|c|c|c|c|c|}
\hline & \multicolumn{2}{|c|}{ Iron (mg/day) } & \multicolumn{2}{|c|}{ Vitamin $C$ (mg/day) } & \multicolumn{2}{|c|}{ Vitamin $D(\mu g /$ day $)$} & \multicolumn{2}{|c|}{ Protein (g/day) } & \multicolumn{2}{|c|}{ Energy (kcal/day)t } \\
\hline & Cows' milk & $\begin{array}{l}\text { Follow-on } \\
\text { formula }\end{array}$ & Cows' milk & $\begin{array}{l}\text { Follow-on } \\
\text { formula }\end{array}$ & Cows' milk & $\begin{array}{l}\text { Follow-on } \\
\text { formula }\end{array}$ & Cows' milk & $\begin{array}{l}\text { Follow-on } \\
\text { formula }\end{array}$ & Cows'milk & $\begin{array}{l}\text { Follow-on } \\
\text { formula }\end{array}$ \\
\hline Enrolment & $5.9(2.9)$ & $5.2(2.8)$ & $31(20)$ & $29(28)$ & $2.6(2.6)$ & $2.4(2.2)$ & $32(6.6)$ & $31(7.5)$ & $835(292)$ & 819 (201) \\
\hline 12 Months & $5.9(2.6)^{\star}$ & $12.3(4.2)^{\star}$ & $22(16)^{\star}$ & $79(26)^{\star}$ & $1.9(2.0)^{\star}$ & $8.0(3.7)^{\star}$ & $40(6.3)^{\star}$ & $30(13)^{\star}$ & $1011(250)$ & $956(160)$ \\
\hline 18 Months & $5.7(2.3)^{\star}$ & $9.2(2.8)^{\star}$ & $24(15)^{\star}$ & $60(29)^{\star}$ & $1.2(1.9)^{\star}$ & $4.9(2.9)^{\star}$ & $42(9.7)$ & $35(10)$ & $1123(220)$ & $1061(205)$ \\
\hline 24 Months & $5.3(1.6)$ & $4.8(1.4)$ & $21(11)$ & $27(21)$ & $1.2(0.7)$ & $0.8(0.4)$ & $36(9.5)$ & $38(8)$ & $1083(229)$ & 1054(195) \\
\hline
\end{tabular}

${ }^{\star} \mathrm{p}$ Value: $<0.001$

$+1 \mathrm{kcal}=4.18 \mathrm{~kJ}$.

No correlation was found between haemoglobin and ferritin concentrations in the cows' milk group at any age, but this may have been due to insufficient ferritin samples at the appropriate ages.

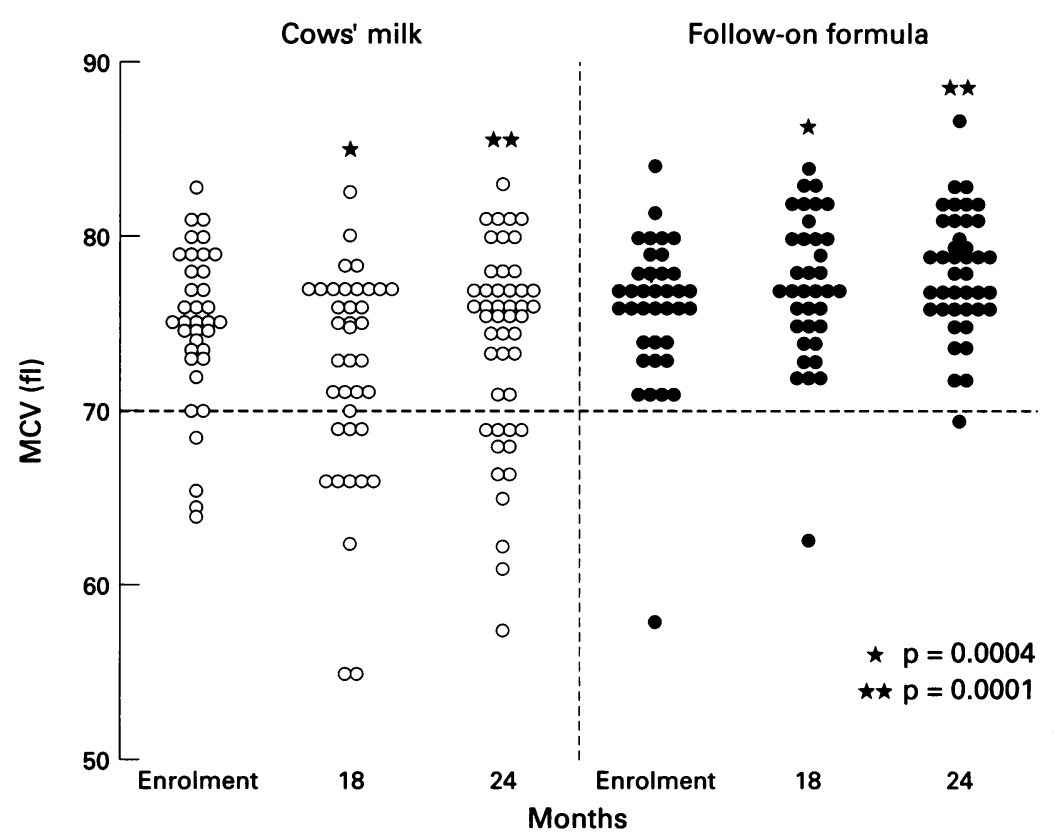

Figure 2 Change in MCV in the cows' milk and follow-on formula groups at enrolment and at 18 and 24 months.

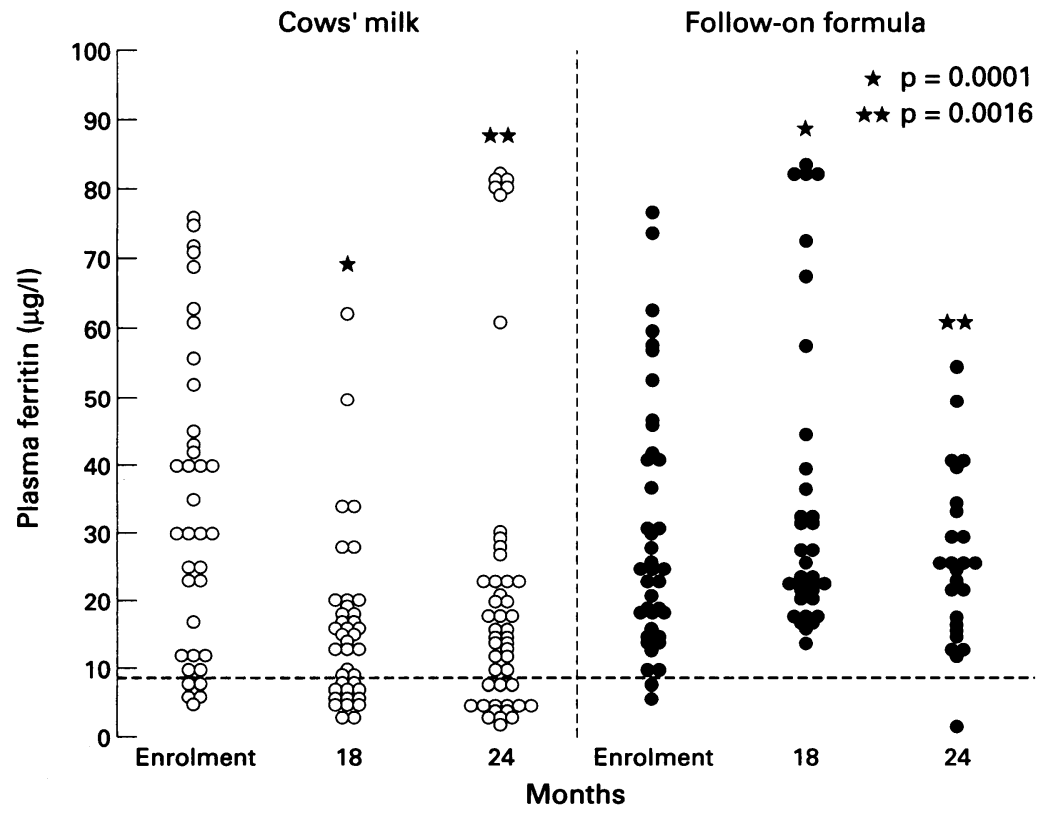

Figure 3 Change in plasma ferritin concentration in the cows' milk and follow-on formula groups at enrolment and at 18 and 24 months.

\section{DIETARY ASSESSMENTS}

Dietary iron (tables 3 and 4 ; fig 4)

Iron intake was low at recruitment. In the two groups overall, iron intake was only $70 \%$ of the reference nutrient intake (RNI) for iron. ${ }^{14}$ However, mean iron intake from milk and solids in the follow-on formula group rose well above the RNI at 12 and 18 months (tables 3 and 4). During the same period, iron intake was significantly lower in the cows' milk group $(p<0.001)$, with mean intakes well below the RNI ( table 4).

Volume of milk consumed (fig 5)

Follow-on formula contributed a substantial proportion of total iron intake. At 12 months, the equivalent of $76 \%$ of the RNI was provided by a mean intake of $582 \mathrm{ml}$ of follow-on formula, whereas a mean intake of $592 \mathrm{ml}$ pasteurised milk provided only $3 \%$ of the RNI for iron in the cows' milk group. At 18 months of age there was a significant difference in the volume of follow-on formulas and cows' milk consumed. The follow-on formula group consumed an average of $378 \mathrm{ml}$ of formula milk compared with $576 \mathrm{ml}$ in the cows' milk group. However, at 18 months of age the follow-on formula group were given on average $160 \mathrm{ml}$ of cows' milk, which was used on cereals and in drinks. Therefore, overall there was no significant difference in the total of milk consumed between the two groups. At 24 months, when both groups were on cows' milk, total dietary iron intake (milk and solids) was again low, with the follow-on formula group receiving only $70 \%$ of the RNI, and the cows' milk group only $77 \%$.

Vitamin C (tables 3 and 4)

At enrolment, mean dietary vitamin $\mathrm{C}$ was $120 \%$ of the RNI in the two groups overall. Between 12 and 18 months, vitamin $C$ intake increased greatly in the follow-on formula group, and provided a mean of $215 \%$ of the RNI, compared with a mean of only $76 \%$ in the cows' milk group during the same period $(p<0.0001)$. Between 12 and 18 months of age, follow-on formula alone provided $166 \%$ of the total RNI for vitamin C intake in the follow-on formula group, while cows' milk only provided $20 \%$ of the requirement in the cows' milk group. At 24 months of age when both groups were on cows' milk, vitamin C intake was again poor in both groups, and cows' milk provided only $14 \%$ of the RNI. 
Table 4 Combined total nutrient intake (milk and solids) for pasturised cows' milk and follow-on formula groups, expressed as mean (SD) percentage of the RNI or EAR

\begin{tabular}{|c|c|c|c|c|c|c|c|c|c|c|}
\hline & \multicolumn{2}{|c|}{ Iron (mg /day) \% RNI } & \multicolumn{2}{|c|}{$\begin{array}{l}\text { Vitamin C (mg/day) \% } \\
R N I\end{array}$} & \multicolumn{2}{|c|}{$\begin{array}{l}\text { Vitamin D ( } \mu g / \text { day }) \% \\
R N I\end{array}$} & \multicolumn{2}{|c|}{ Protein (g/day) \% RNI } & \multicolumn{2}{|c|}{$\begin{array}{l}\text { Energy ( kcal/day) \% } \\
\text { EARt }\end{array}$} \\
\hline & Cows' milk & $\begin{array}{l}\text { Follow-on } \\
\text { formula }\end{array}$ & Cows'milk & $\begin{array}{l}\text { Follow-on } \\
\text { formula }\end{array}$ & Cows'milk & $\begin{array}{l}\text { Follow-on } \\
\text { formula }\end{array}$ & Cows' milk & $\begin{array}{l}\text { Follow-on } \\
\text { formula }\end{array}$ & Cows' milk & $\begin{array}{l}\text { Follow-on } \\
\text { formula }\end{array}$ \\
\hline $\begin{array}{l}\text { Enrolment } \\
12 \text { Months } \\
18 \text { Months } \\
24 \text { Months }\end{array}$ & $\begin{array}{l}76(37) \\
76(33)^{\star} \\
82(33)^{\star} \\
77(23)\end{array}$ & $\begin{array}{c}67(36) \\
158(54)^{\star} \\
133(41)^{\star} \\
70(20)\end{array}$ & $\begin{array}{c}123(80) \\
88(64)^{\star} \\
80(58)^{\star} \\
84(44)\end{array}$ & $\begin{array}{l}116(112) \\
317(104)^{\star} \\
200(96)^{\star} \\
108(70)\end{array}$ & $\begin{array}{l}37(37) \\
27(29)^{\star} \\
18(27)^{\star} \\
17(10)\end{array}$ & $\begin{array}{c}34(31) \\
114(53)^{\star} \\
70(41)^{\star} \\
11(6)\end{array}$ & $\begin{array}{l}235(48) \\
268(42)^{\star} \\
289(67) \\
248(65)\end{array}$ & $\begin{array}{l}226(53) \\
201(87)^{\star} \\
241(69) \\
262(53)\end{array}$ & $\begin{array}{r}105(36) \\
113(28) \\
94(18) \\
90(19)\end{array}$ & $\begin{array}{r}103(25) \\
107(18) \\
85(17) \\
88(14)\end{array}$ \\
\hline
\end{tabular}

${ }^{\star} \mathrm{p}$ Value: $<0.001$.

$+1 \mathrm{kcal}=4.18 \mathrm{~kJ}$.

Energy (tables 3 and 4)

There was no significant difference in energy intakes between groups at any point in the

Cows' milk

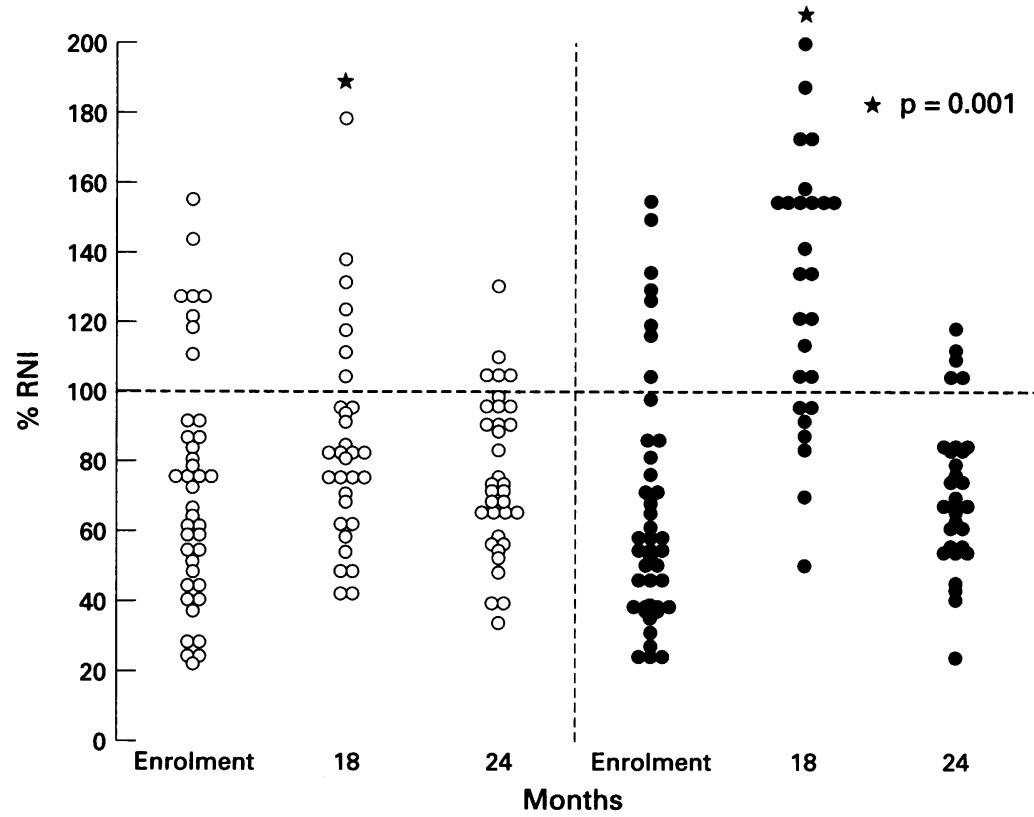

Figure 4 Dietary iron intake expressed as a percentage of the RNI for the cows' milk and follow-on formula groups at enrolment and at 18 and 24 months.
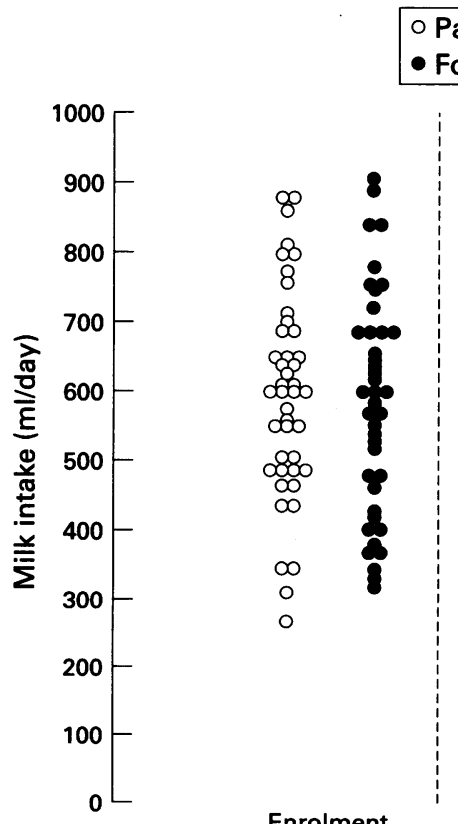

O Pasteurised cows' milk - Follow-on formula

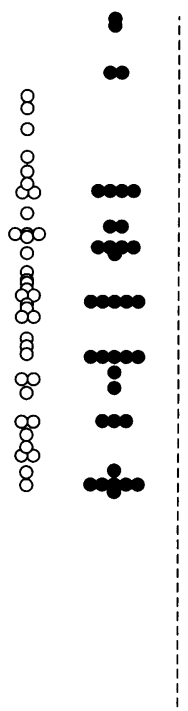

12

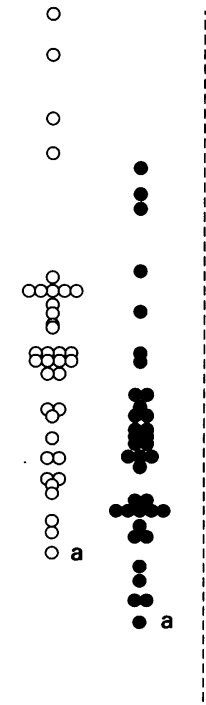

Months

Figure 5 Milk intakes in the cows' milk and follow-on formula groups.

study. At enrolment and 12 months, energy intake was in excess of the estimated average requirements (EAR) in both groups. By 18 months, energy had decreased as a percentage of the EAR in both groups and remained below it until 24 months. At 18 months, cows' milk provided $32 \%$ of the EAR for energy in the cows' milk group and follow-on formula provided $20 \%$ of the EAR in the follow-on formula group.

GROWTH

Both groups of children grew satisfactorily on both follow-on formula and cows' milk. There were no significant differences in $\mathrm{z}$ scores for weight for age, height for age, or weight for height between the two groups or between the groups and reference values at enrolment and at 12,18 , or 24 months.

\section{Discussion}

This randomised, cohort study, carried out in a group of infants at high risk of developing iron deficiency, showed that the provision of a follow-on formula in place of pasteurised cows' milk between 7.8 and 18 months of age was effective in preventing anaemia.

It seems highly likely that the high incidence of anaemia in the group receiving pasteurised cows' milk was due to iron deficiency. Firstly, there were substantial differences between the two groups with respect to other indices of iron status: MCV and plasma ferritin. Secondly, the

infants were already receiving pasteurised cows' milk by 6 months of age, and in the two study groups combined, $12 \%$ already had a haemoglobin of $<110 \mathrm{~g} / 1$ at enrolment. The frequency of anaemia increased in the group randomised to continue on cows' milk, so that by 18 months, one third of the group were anaemic. In contrast, only $2 \%$ of the group receiving follow-on formula from enrolment to 18 months were anaemic, and this benefit was carried over to 24 months of age, when none had a haemoglobin of $<110 \mathrm{~g} / \mathrm{l}$, even though they had returned to cows' milk six months before. These differences in the frequency and anaemia are both statistically and clinically sig- 
nificant. However, we would accept that the differences in mean haemoglobin concentration at 24 months $(6.0 \mathrm{~g} / \mathrm{l})$ between the two groups was of doubtful clinical significance, albeit statistically so.

Examination of the dietary data excluding milk shows no significant differences in nutrient content of the diets between the follow-on formula and cows' milk groups The dietary assessments confirmed that in the absence of an iron fortified formula, the iron intake from other sources (solids) by these infants was insufficient to provide enough iron to meet the RNI. Before randomisation, iron intake in the two groups overall, was only $71 \%$ of the RNI. Although this was substantially boosted between enrolment and 18 months, in the group receiving follow-on formula, the intake in both groups had again become inadequate by 24 months, six months after the follow-on formula group had reverted to cows' milk. Such children are therefore at risk of iron deficiency, not only during infancy, but for at least part of their preschool years, and possibly longer.

Although we have compared our data with the RNI, caution is needed when interpreting such results. Nutrient intakes below the RNI by an individual are not necessarily inadequate. However, when the number of individuals in a group with a low intake is extensive, the risk of deficiency in that population is increased. Our data would suggest that the cows' milk group were a population at risk of iron deficiency anaemia. A further question arises: does achieving the RNI for iron guarantee an iron sufficient state? Duggan et al observed no association between biochemical iron status and the dietary intake of energy or iron. ${ }^{4}$ Both the biochemically iron deficient and non-deficient children had low levels of dietary iron intake. An important consideration in the dietary intake of iron is its availability; in our survey, as with that of Mills, ${ }^{7}$ children taking formula milk were protected against iron deficiency anaemia. The question over absorption of iron from formula milk has been debated. Studies have shown that only $4 \%$ of iron from a follow-on formula compared with $6 \%$ in a standard infant formula is absorbed. ${ }^{15}{ }^{16}$ However, our results would suggest that adequate iron is absorbed from follow-on formulas as haemoglobin status in the follow-on formula group is maintained even when low volumes are consumed at 18 months of age.

We have no data on the frequency of iron deficiency or on the use of cows' milk in the population of inner city infants from whom we drew our sample. In order to conduct a study which was ethically justified, we enrolled only those infants whose caretakers had already switched to cows' milk by 6 months of age (in contrast to their health visitors' advice). Nor do we have data on why such a switch was made, although it is our impression that ease of use and family tradition rather than cost, were major considerations. Our sample may therefore be biased towards a particularly nutritionally disadvantaged group of subjects, within a population already exposed to considerable social deprivation. However, similar studies in the UK and the US have provided broadly similar frequencies of anaemia in unselected samples of urban toddlers. ${ }^{131718}$ We do not feel therefore, that our data grossly misrepresent the situation among inner city infants and toddlers as a whole.

Although energy and protein intakes were adequate in subjects randomised to continue on cows' milk, their intakes of vitamin $C$ and $D$ were inadequate throughout all or most of the study period. These infants are therefore vulnerable not only to iron deficiency, but also to other micronutrient deficiencies. This was reflected in the poor nutrient content of the foods offered and the low usage of supplementary vitamin drops: of the sample recruited, only $9 \%$ of the mothers used vitamin supplementation, and only then on an ad hoc basis.

By 6 months of age, most infants were receiving home prepared solids. Commercial weaning foods were used for only a short time, generally between 12 and 15 weeks of age. Home based foods were favoured. They were cheaper and easier to prepare with the family meal, although they were lower in iron and vitamins $\mathrm{C}$ and $\mathrm{D}$. Tinned soups and spaghetti, fish fingers, and baked beans were popular, while meat based dishes were eaten in only small quantities (approximately 25-35 g per portion). The majority of iron in the weaning diet was provided by non-haem iron sources. Fresh fruit and vegetables were expensive to buy locally and not given on a daily basis.

Finding an acceptable method of preventing iron deficiency anaemia in infants and toddlers has been difficult. In the UK, infant foods are often fortified with iron, but no accurate data exist on the effective absorption of iron from these foods. ${ }^{15} 19$ Difficulties are found in fortifying these foods due to rancidity and discoloration. Walter showed that infant cereals fortified with iron and vitamin $C$ could be effective in preventing iron deficiency anaemia. ${ }^{20}$ However, the dietary data in our study showed that commercially prepared infant foods were used for only a short time and therefore the benefit of using such measures is likely to be short lived (data not shown).

Another approach that has been successful in preventing iron deficiency anaemia has been the use of iron fortified formulas. In the early 1970s the USA introduced the Women Infant and Child (WIC) programme. This provided nutritional support for pregnant women, infants, and children in low income families. Infants were provided with an iron fortified milk $(1.2 \mathrm{mg} / 100 \mathrm{ml})$ similar to the follow-on formula milk available in the UK, and from 6 months of age with iron and vitamin C-rich infant foods. Yip showed that the prevalence of anaemia among low income children had fallen from $7.8 \%$ in 1975 to $2.9 \%$ in 1985 , and this change was largely attributed to the WIC programme. ${ }^{21}$ Other studies comparing the use of an iron fortified formula with a low iron formula have demonstrated similar findings and supported the use of an iron fortified formula in the prevention of iron deficiency anaemia. ${ }^{52}$ 
Mills showed that a standard infant formula was effective in preventing iron deficiency anaemia, and that continued feeding with breast milk and the early introduction of cows' milk were associated with a higher prevalence of anaemia. ${ }^{7}$ This study was retrospective, detailed dietary data were not collected, and the long term effects of feeding formula milk beyond 12 months of age were not investigated.

There has been little work on the role of follow-on formulas. At 18 months of age in our study group, only $1 \%$ of the infants in the follow-on formula group were anaemic, and the benefit of using this milk was present 6 months after the milk was stopped. At 18 months of age an average intake of $378 \mathrm{ml}$ of follow-on formulas provided $65 \%$ of the RNI for iron. A recent study by Stevens and Nelson has shed further light on the pathogenesis of iron deficiency anaemia in toddlers. ${ }^{23}$ Their study compared the haematological outcomes in infants randomised to receive either an otherwise identical iron, or a non-iron supplemented follow-on formula. No difference in the frequency of iron deficiency anaemia was present between groups, which in each group was much lower than seen in our study. Interestingly, dietary intake of iron was actually slightly higher in their subjects than in our cows' milk group. Their findings, when combined with ours, would suggest that the deleterious effects of cows' milk may not be entirely related to its low iron content, and that other factors, such as induction of occult blood loss, may be more relevant.

The question arises as to whether similar results could have been obtained using a standard infant formula instead of a follow-on formula. The follow-on formula used in this study differs from the standard infant formula made by the same manufacturer in a number of respects (table 1). In particular, nearly twice as much iron is present in the follow-on formula $(1.2 v 0.65 \mathrm{mg} / 100 \mathrm{ml})$, and there is $45 \%$ more vitamin C $(10.0 v 6.9 \mathrm{mg} / 100 \mathrm{ml})$. Using our dietary assessment data, we calculated the intakes of iron which would have been provided by follow-on formulas and standard infant formula at 12 and 18 months if the same volume of standard infant formula instead of follow-on formula had been consumed. If the same volume of standard infant formula (in addition to solids ) had been given instead of follow-on formula, substantially more of the children would not have achieved the RNI for iron. Thus, when the consumption of ironcontaining solids by infants and toddlers is particularly low, as it often is in economically deprived families, providing a follow-on formula may be an important safety net to more children than a standard infant formula. However, as we have already pointed out, the avoidance of cows' milk rather than absolute iron intake may be more important in preventing iron deficiency.

Does preventing this high frequency of iron deficiency matter? Recently, attention has focused on a possible link between iron deficiency anaemia in toddlers and delayed cognitive development. For example, iron deficient toddlers in Birmingham who received an oral iron supplement experienced significantly faster acquisition of developmental skills than a group randomised to receive placebo. ${ }^{24}$ While similar observations have been made in a number of other intervention studies, ${ }^{25-27}$ it has not always been possible to show beneficial effects on cognitive development in longitudinal cohort studies, nor has the biochemical basis of a possible effect been defined. However we are sufficiently persuaded by the available evidence on delayed cognitive development to recommend that active measures are taken to prevent iron deficiency in at-risk infants and toddlers.

Our data highlight a potential anomaly in the provision of free milk to infants and toddlers in low income families in the UK. Pasteurised cows' milk is available free of charge, even though its use places children who are likely to be receiving iron deficient intakes of solids at an even higher risk of iron deficiency. While the continuing provision of standard infant formula is important, our data suggest that many deprived toddlers may have an intake of iron and vitamin $C$ from other sources which is so low, that only by receiving the additional supplementation present in a follow-on formula, can they bring their intakes of these nutrients above the $\mathrm{RNI}$.

We would like to thank all the health visitors at Nechells Health Centre without whose support and encouragement the project would not have been possible, the mothers who took part, and Farleys for financial support.

1 Ehrhardt $P$. Iron deficiency in young Bradford children from different ethnic backgrounds. $B M Y$ F 1986; 292: 90-3.

2 James J, Lawson P, Male P, Oakhill A. Preventing iron deficiency in pre-school children by implementing an educational and screening programme in inner-city practice. $B M \mathcal{F} 1989 ; 299: 838-40$.

3 Madder E, Wilcoll A, Polnay L, Shulman CE. Discovering anaemia at child health clinics. Arch Dis Child 1990; 65: 892-4.

4 Duggan MD, Steel G, Elwys G, Harbottle L, Noble C. Iron status, energy intake and nutritional status of healthy young Asian children. Arch Dis Child 1991; 66: 1386-9.

5 Pizarro F, Yip R, Dallman P, Olivares M, Hertrampf E, Walter $T$. Iron status with different infant feeding Werimens. Relevance to screening and prevention of inon deficiency. $\mathcal{F}$ Pediatr 1991; 118: 687-92.

6 Dallman PR, Yip R, Johnson C. Prevelance and cause of anaemia in the United States 1976-1980. Am f Clin Nutr 1984; 84: 437-45.

7 Mills AF. Surveillance for anaemia risk factors in patterns of milk intake. Arch Dis Child 1990; 65: 428-31.

8 Woodruff CW, Wright SW, Wright RP. The role of fresh cow's milk with a prepared formula. Am $\mathcal{F}$ Dis Child 1972 124: 26-30.

9 Sullivan P. Cows' milk induced intestinal bleeding in infancy. Arch Dis Child 1993; 68: 240-3.

10 Fuchs G, Dewier M, Hutchinson S, Sundeen M, Schwart S, Suskind R. Gastrointestinal blood loss in older infants: impact of cow's milk versus formula. $\mathcal{f}$ Pediatr Gastroenterol Nutr 1993; 16: 4-9.

11 European Society for Paediatric Gastroenterology and Nutrition (ESPGAN). Commitree on Nutrition GuideNutrition (ESPGAN). Committee on Nutrition Guide位 position of follow on formula and beikost. Acta Paediat

12 Holland B, Welch AA, Unwin ID, Buss DH, Paul AA, Southgate DAT. McCance and Widdowson's The composition of foods. 5th Ed. Cambridge: Royal Society of Chemistry, Ministry of Agriculture, Fisheries and Food, 1991.

13 Hamill PVV, Drizd TA, Johnson CLT, Reed RB, Rocho AF, Moor W. Physical growth. National Center for Health Statistics percentiles. Am $\mathcal{F}$ Clin Nutr 1979; 32: 607-29.

14 Department of Health. Dietary reference values for food, energy and nutrients for the United Kingdom. Report on health and social subjects No 41. London: HMSO, 1991.

15 Rios E, Hunter RE, Cook JD, Smith WJ, Finch CA. The absorption of iron as supplements in infant cereals and infant formulas. Pediatrics 1975; 55: 686-93.

16 Dallman PR. Iron deficiency in the weanling-a nutritional problem on the way to resolution. Acta Paediatr Scand Suppl 1986; 323: 59-67. 
17 Mc Phail AP, Bothwell TH. Fortification of the diet as a stratergy for preventing iron deficiency. Acta Paediat Scand Suppl 1989; 361: 114-24.

18 Miller V, Swaney S, Deinard A. Impact of the WIC programme on the iron status of low income infants. Pediatrics 1985; 75: 100-3.

19 Formon SJ. Bioavaliablility of supplemental iron in commercially prepared dry infant cereals. F Pediatr 1987; 110: 660-1.

20 Walter T, Dallman P, Pizarro F, et al. Effectiveness of iron fortified infant cereal in prevention of iron deficiency anaemia. Pediatrics 1993; 91: 976-82.

21 Yip R. The changing characteristics of childhood iron nutritional status in the United States. Dietary iron: birth to two years. status in the United States. Dietary iron: birth

22 Irigoyen M, Davidson LI, Carrioro D, Seaman C Randomised, placebo controlled trial of iron supplementation in infants with low haemoglobin levels fed iron fortified formula. Pediatrics 1991; 88: 320-6.

23 Stevens D, Nelson A. The effect of iron in formula milk after 6 months of age. Arch Dis Child 1995; 73: 216-20.
24 Aukett MA, Parks YA, Scott PH, Wharton BA. Treatment with iron increases weight gain and psychomotor development. Arch Dis Child 1986; 61: 849-58.

25 Oski FA, Honig AS, Helu B, Howanitz P. Effect of iron therapy on behaviour performance in nonanemic iron deficient infants. Pediatrics 1989; 84: 9-17.

26 Walter T, Kovalskys J, Stekel A. Effect of mild iron deficiency on infant mental developmental scores. $f$ deficiency on infant mental

27 Hoing AS, Oski FA. Developmental scores of iron defcient infants and the effects of therapy. Infant Behaviour and Development 1978; 1: 168-76.

28 Department of Health and Social Security. Artificial feeds for the young infant. DHSS report on health and social subjects No 18. London: HMSO, 1980.

29 Farley Health Products. Follow-on formula. Kendal: Farley Health Products, 1992.

30 Farley Health Products. Standard infant formula. Kendal: Farley Health Products, 1993. 